\title{
PESQUISA ACADÊMICA SOBRE PROFESSORES EM INTERLOCUÇÃO COM O PLANO NACIONAL DE EDUCAÇÃO (PNE 2014-2024): EPISTEMOLOGIAS, CONFLUÊNCIAS E CONTRADIÇÕES ${ }^{1}$
}

Ruth Catarina Cerqueira Ribeiro de Souza Solange Martins Oliveira Magalhães

RESUMO: Este artigo propõe-se a interpelar a epistemologia da produção do conhecimento sobre educação, professores, sua formação e profissionalização, tanto na academia quanto na política voltada à educação, especificamente no documento que legisla a educação brasileira nos próximos dez anos: o PNE 2014-2024. O ponto de partida são suas epistemologias e historicidades. Trata-se dos resultados de uma ampla pesquisa desenvolvida em Rede, que analisa a produção acadêmica sobre professores a partir da base teórico-metodológica da dialética. Na articulação do trabalho em Rede, esse proceder busca fazer entender aos pesquisadores do campo como sua atividade investigativa credita posições ideológicas, que sustentam fins e meios à produção do conhecimento, logo à qualidade da formação e da educação. Neste trabalho apresenta-se um recorte no que se refere às produções do Programa de Pós-graduação em Educação, Faculdade de Educação/UFG, desenvolvidas a partir da base dialética, no período de 1999-2009, em que foram defendidos 317 trabalhos. Desse total, 93 versaram sobre a temática professores. Na análise, destacam-se os indicadores de qualidade social, método, ideário pedagógico e formação, construídos pela Rede. Entende-se que a epistemologia da prática sustenta a posição hegemônica, consolidando uma concepção mercadológica para a educação; a epistemologia da práxis é contra-hegemônica e, como tal, expressa a resistência à política neoliberal, exigindo qualidade social para a educação. Ambas sustentam princípios e fundamentos que podem fazer com que o campo da produção acadêmica produza ações contra-hegemônicas ou contribua para o consenso ativo e a política de Terceira Via e o reforce. Adotou-se, também, a epistemologia como ponto de partida da análise sobre a temática - Plano Nacional de Educação -, colocando-a em relação à produção acadêmica, com foco na formação e na educação. Identificou-se que, no caso da produção acadêmica, no período 1999-2007, há a presença da racionalidade da epistemologia da prática, o que favorece a construção de conceitos que atendem às demandas neoliberais. No período seguinte, 2008-2009, há a predominante presença da epistemologia da práxis, cuja racionalidade respeita as mediações de caráter histórico, cultural e social, como processo fundante de desenvolvimento do ser social, da humanização do homem, caracterizando a produção do período como contra- hegemônica. No campo da produção do conhecimento, como no caso do PNE, expressam-se forças antagônicas que se confrontam. No caso da política expressa no PNE, a epistemologia da prática mostra-se predominante na produção das racionalidades que fortalecem a hegemonia. Conclui-se a necessidade da cautela epistemológica e alertase para a concepção de qualidade proposta à formação de professores e à educação no documento.

PALAVRAS-CHAVE: PNE; Políticas Educacionais; Pesquisa Acadêmica; Epistemologia; Professores. 


\title{
autêntica
}

\begin{abstract}
In this article, we analyze the epistemology of production of knowledge on education, teachers, their training and professionalization, in academia and in education policy, specifically in the document you want to legislate Brazilian education in the next decade: the National Education Plan - PNE. The starting point is their epistemology and historicity, the route involves the results of a comprehensive survey conducted in network that reviews academic literature on teachers from the theoretical and methodological basis of dialectics. The research aims to understand the researchers of the field, as their research activity, promotes ideological positions that support ends and means of knowledge production, the quality of training and education. In this work, we present a cut in relation to production of the PostGraduate Education, Faculty of Education / UFG, developed from the dialectic base 1999-2009 period. During that time, they defended 317 jobs, of this total 93 were about the subject teachers. In the analysis, we highlight the of social quality indicators method, pedagogical ideas and training, built by Network. It is understood that the epistemology of practice sustains the hegemonic position, consolidating a marketing conception for education; the epistemology of praxis is against hegemonic, expresses the resistance to neoliberal policy, requires social quality for education. In both epistemological bases, there are principles and theoretical bases that can cause the field of academic research produces action against hegemonic or strengthen the consensus proposed by the neoliberal policy. It was also adopted epistemology as a point of analysis of the National Education Plan, placing it in relation to academic research, focusing on training and education. It was found that in the case of the production for the period 1999-2007, there is the presence of the practical rationality epistemology, which favors the construction of concepts that meet the demands neoliberal. In the following period (2008-2009) there is a predominance of praxis epistemology, whose rationality respects the historic character of mediations, cultural and social, as social development process, humanization of man, characterizing the production period as against hegemonic. In the field of production analyzed, as in the case of PNE, is expressed opposing forces. In the case of PNE there is the presence of epistemology of practice, this appears to be prevalent in the rationalities of training to strengthen the neoliberal hegemony. The conclusion is the need for epistemological caution in the execution of a quality project for teacher training and education in the document.
\end{abstract}

KEYWORDS: PNE; Educational Policy; Academic research; epistemology; Teachers. 


\section{autêntica}

\section{INTRODUÇÃO}

A produção do conhecimento constitui-se instrumento de diferentes usos políticos, podendo assumir a perspectiva hegemônica ou contra-hegemônica, servindo, assim, aos interesses mercadológicos ou aos anseios de libertação. Apesar de ser denominado público, o conhecimento produzido no interior das universidades traz muitos sinais dos interesses privados. Este artigo propõe-se a interpelar a epistemologia da produção do conhecimento, tanto no discurso acadêmico como no discurso político voltado à educação, formação e profissionalização dos professores, especificamente o documento que planeja a educação brasileira para os próximos dez anos: o Plano Nacional de Educação (PNE 2014-2024).

Muitos autores vêm trabalhando em relevantes análises desse documento. Com este artigo, pretende-se contribuir para essa tarefa, a partir de uma reflexão epistemológica que abranja os aspectos ontológicos explicitados nesse documento. Como a produção do conhecimento não é neutra, a análise da construção e das finalidades dos trabalhos acadêmicos ajuda a compreender se seus objetivos estão a serviço da manutenção dos interesses mercadológicos ou dos emancipatórios. As epistemologias presentes na produção acadêmica e na legislação educacional mostram tanto confluências epistemológicas como embates e contradições.

Neste trabalho, apresentam-se reflexões sobre o PNE 2014-2024, colocando-o em relação à formação e à educação, tendo como pontos de partida sua epistemologia e historicidade. A análise apoia-se nas contribuições de Tello (2013) para apresentar a concepção da epistemologia aqui assumida. Para esse autor, a epistemologia se compõe da perspectiva epistemológica - teoria geral, do posicionamento epistemológico -, cosmovisão, que se transforma em posicionamento político ideológico, a partir do qual o pesquisador desenvolverá seu trabalho. O enfoque epistemológico implica escolha metodológica, ou o "modo de pensar o logos". Nesse sentido, a metodologia passa a ser epistemetodologia, na qual convergem a apresentação do método e o caminho estruturado para a pesquisa. A epistemologia assume conotação social, política, cultural e, quando associada à opção crítica contra-hegemônica, transforma-se em posicionamento ético-político de caráter emancipador.

Ao tratar epistemologicamente da relação entre o PNE, formação docente e a educação, discute-se o estudo das possibilidades, da legitimidade, do valor e dos limites do conhecimento científico, movimento que não pode deixar de considerar a mediação entre teoria e prática que o constitui, bem como sua capacidade de influir na práxis dos professores (SAVIANI, 2013).

Neste artigo, sustenta-se essa discussão de epistemologia e apresentam-se resultados parciais de um dos trabalhos desenvolvidos pela Rede de pesquisadores sobre professores do Centro-Oeste/Brasil (Redecentro), que analisa a produção acadêmica sobre professores. Trata-se de uma ampla rede composta por sete Programas de Pós-Graduação em Educação da Região: Universidade de Brasília (UnB), Universidade Federal de Mato Grosso (UFMT), Universidade Federal de Mato Grosso do Sul (UFMS), da Universidade Federal de Goiás (UFG), Universidade Federal de Uberlândia (UFU), Universidade Federal do Tocantins (UFT) e Universidade de Uberaba (UNIUBE), agregadores de vários projetos de pesquisas, cujas temáticas têm centralidade no professor. Coletivamente, o trabalho em rede mostra-se essencialmente colaborativo e, particularmente, formativo.

Por meio de seus componentes, a Redecentro desenvolve uma investigação metateórica, avaliando qualitativamente uma década da produção - período de 1999 a2009. A Rede realiza uma pesquisa sobre pesquisas, com abordagem qualitativa, pautada no método materialista histórico-dialético, a partir do posicionamento ético-político e metodológico crítico contra-hegemônico. 
São objetivos da Rede: a) promover a reflexividade sobre as concepções construídas nos trabalhos acadêmicos, para que eles sustentem maior solidez epistemológica; b) apoiar a oposição ao modelo ateórico e meramente descritivo das questões educacionais, verificado em muitas produções, entendendo que essa opção torna as produções um campo mantenedor da hegemonia, sobretudo quando construídas a partir da epistemologia da prática.

$\mathrm{Na}$ articulação do trabalho em rede, busca-se fazer entender aos pesquisadores como sua atividade investigativa credita posições ideológicas, que sustentam fins e meios à produção do conhecimento e à qualidade da formação e da educação. Assim, a Redecentro esboça proposições que não devem ser compreendidas como modelos nem como certezas, mas aceitas, na interlocução do debate, como sugestões e alternativas para os que se interessam e são responsáveis pela produção do conhecimento.

Para alcançar seus objetivos, a Rede estruturou categorias de análise: temas desenvolvidos (formação, profissionalização, trabalho docente), tipo e abordagem de pesquisa, método, ideário pedagógico, referencial teórico utilizado. Essas categorias, quando articuladas, dizem do posicionamento epistemológico, metodológico e político, que identificam o movimento ideológico das pesquisas.

A partir dos trabalhos desenvolvidos até o momento ${ }^{2}$, pode-se observar que parte da produção acadêmica apresenta formulações críticas, portanto contra-hegemônicas, e outra parte, acríticas, o que pode fazê-la referendar a aceitação e a afirmação das políticas educacionais neoliberais, com o consequente empresariamento dessa produção (SOUZA; MAGALHÃES, 2014). Considera-se que o conhecimento exerce a função de regulação, na medida em que ao ser publicizado ratifica e legitima decisões políticas em suas racionalidades. Portanto, a perspectiva epistemológica ampara posições ideológicas que são a base da construção e implantação de políticas de formação docente, como é o caso do PNE.

Seguindo a proposta metodológica da Redecentro, a análise coloca o foco nas concepções de epistemologia da prática e epistemologia da práxis para identificar e compreender os princípios que sustentam a concepção de qualidade da educação, seus efeitos nas concepções de formação e de ideário pedagógico. Questionamse as repercussões dessas escolhas na elaboração de políticas para a formação docente e nas práticas de formação de professores.

\section{DA EPISTEMOLOGIA DA PRÁTICA À EPISTEMOLOGIA DA PRÁXIS: FUNDAMENTOS, PRINCÍPIOS, CONCEITOS E POSICIONAMENTO POLÍTICO.}

Duarte (2000) refere-se à epistemologia da prática como teoria do conhecimento que se caracteriza como peculiar, individual, não incorporada pela racionalidade científica. Organiza-se a partir do conhecimento pragmático, adota a concepção dicotômica da relação teoria e prática com a primazia desta, ou seja, a prática é posta como suficiente para o conhecer, é tomada em seu sentido utilitário, ao mesmo tempo em que se contrapõe à teoria, que é compreendida como de menor relevância. Portanto, a prioridade é conferida à prática, mas sem teoria, ou com um mínimo dela, respondendo ao praticismo ou ao pragmatismo. Reafirma-se o conhecimento como apropriação individual da realidade objetiva, portanto parcial e limitado à percepção imediata.

Para a epistemologia da prática, a concepção de educação é a tradicional e se mostra sem perspectivas de transformação social. Professores e alunos são tomados como a-históricos. Professores são especialistas, 


\section{autêntica}

dos quais não se exige entender a estrutura e as relações interdisciplinares de sua disciplina, nem, muito menos, a realidade histórica e sociocultural na qual está envolvido. Alunos são fiéis depositários do conhecimento, cabendo a eles armazenar e repetir o conteúdo dado, não se admitindo, para isso, a interferência do pensamento e da experiência própria. O ensino, portanto, é efetivado por meio de metodologias reprodutivas na transmissão dos conteúdos, e a aprendizagem, por meio de memorização, mantendo-se o pensamento acrítico e ingênuo.

Reifica-se uma concepção de formação mecanicista e instrumental que dota professores de técnica, habilidades e competências, para responder eficientemente às exigências do capital. No conjunto, essa base epistemológica sustenta a aceitação do conceito de qualidade neoliberal com valor mercadológico, relacionada à mercantilização da educação.

A partir da proposta apresentada para o estudo da epistemologia, pode-se concluir que a formação e a educação nessa perspectiva - epistemologia da prática - é o positivismo. O posicionamento político-ideológico é o neoliberal, que se caracteriza, entre outros atributos, por não apresentar perspectivas de transformação social e por compreender as relações sociais como dadas e não como históricas. O enfoque epistemológico, que representa a opção metódica do pesquisador na produção do conhecimento, é filiado ao método positivista.

À epistemologia da prática opõe-se à epistemologia da práxis, cujo caráter mediador exige que a articulação entre teoria e prática seja remetida ao plano do método materialista histórico-dialético, por ser este o que propicia, por intermédio de suas categorias, a compreensão da produção do conhecimento como práxis. Reconhece-se o valor teórico da prática e o valor prático da teoria, ressaltando, portanto, a importância da unidade teoria-prática para os processos de produção do conhecimento e de compreensão da realidade.

O conceito de práxis, categoria fundante desse posicionamento epistemológico, é compreendido como atividade social humana. Esse conceito é fundamental para o entendimento dos processos de elaboração de conhecimento e de formação humana referida à "omnilateralidade". A categoria práxis possibilita que as relações necessárias à produção do conhecimento não sejam dissociadas, mas ligadas e em observância da unidade dinâmica (VÁSQUEZ, 1986). Portanto, é a partir da relação dialética entre teoria e prática que se tem a base da construção do conhecimento.

Quanto à concepção de educação, desloca-se o enfoque do individual para o social, para o político e para o ideológico. Quando assentada no fundamento epistemológico do materialismo histórico-dialético, a educação é contextualizada e historicamente localizada; é processo que liberta pela conscientização (VYGOTSKI, 1995); é ação que promove trabalho igualitário e dialógico, portanto, culturalmente político (FREIRE, 1997). Das teses do materialismo histórico-dialético relativamente à educação podemos entender como as mudanças das "formas de produção da existência humana foram gerando, historicamente, novas formas de educar, as quais, por sua vez, exercem influxo sobre o processo de transformação do modo de produção correspondente" (SAVIANI, 1991, p. 10).

Ainda sobre a tutela do fundamento epistemológico da dialética, o ensino torna-se processo ensino-aprendizagem. Esse processo é contra a homogeneização como paradigma; traz a possibilidade de construir modos coletivos de ensinar e aprender, para ir além dos limites impostos pela lógica neoliberal, que impõe a individualidade como valor, e transgredir a ordem estabelecida.

O professor é sujeito crítico emancipado, cujo trabalho é problematizador, intrinsecamente político, e afeta as escolhas dos sujeitos envolvidos no processo. Sua função social é promover a transformação da sociedade 
por meio da educação da classe do proletariado. Conforme Saviani (2003, p. 55), a classe dominada precisa dispor do saber/conhecimento historicamente produzido, para superar a dominação e fazer desse conhecimento um instrumento de emancipação: “(...) dominar o que os dominantes dominam é condição de libertação". Quanto ao aluno, como afirma Freire (1997, p. 21), esse é "um ser histórico, inserido num permanente movimento de procura, faz e refaz constantemente o seu saber"; é sujeito ativo, envolvido num processo de formação geral na direção de uma educação integral.

A epistemologia da práxis sustenta uma concepção de formação que exige mediações de caráter histórico, cultural e social, as quais sustentam um processo basilar de desenvolvimento do ser social e da humanização do homem (SOUZA; MAGALHÃES, 2014). Essa concepção de formação assume a centralidade do trabalho, que faz a mediação entre teoria e prática. Pelo trabalho, a prática, ao se fazer presente no pensamento, transforma-se em teoria; pelo trabalho também, a teoria se faz prática, desenhando as possibilidades de transformações da realidade.

Conforme essa epistemologia, o conceito de qualidade refere-se à expectativa social; pauta-se, principalmente, sobre o pilar da emancipação, em que as relações se constituem no binômio sujeito-sujeito, procurando alcançar a solidariedade (SANTOS, 2000). Nesse sentido, a relação sujeito-objeto se fortalece e a formação passa a ser geradora de um pensamento independente, crítico, que não se atrela ao processo produtivo, e nega que forças externas imponham o patamar de uma qualidade que essa formação não orientou.

Após análise dos princípios, fundamentos, conceitos, posicionamentos político e metodológico da formação e da educação fundadas na epistemológica da práxis, pode-se concluir que ela sustenta uma postura crítica na construção de concepções acadêmica, pedagógica e política. Essa construção fundamenta o posicionamento político contra-hegemônico, vinculado ao marxismo, o qual exige a luta pela superação das condições sociais de desigualdade geradas pelo capitalismo, que viabilizam a realização da humanização e da cidadania (KUENZER, RODRIGUES, 2007). Essa luta transforma a "inquietude em energia emancipatória" (SANTOS, 2000, p. 346), na qual confluem movimentos vinculados a projetos sociais e econômicos, definidores de tendências pedagógicas que, historicamente, dão vigor à atividade emancipatória do nosso tempo.

\section{FORMAÇÃO E EDUCAÇÃO: POSICIONAMENTOS EPISTEMOLÓGICOS E POLÍTICOS}

Ao se refletir sobre as epistemologias, seus princípios e concepções, pode-se inferir que as escolhas epistemológicas dos professores-pesquisadores sustentam um ethos acadêmico que marca o conhecimento produzido, a formação, a educação. As racionalidades sustentadas alimentam a construção de políticas educacionais, que também defendem valores, crenças, ideias, interesses, posicionamentos de seus autores. Essas racionalidades servem de suporte a reformas sociais e se instalam como campo de manifestação de contradições. Esses aspectos têm sido destacados em vários estudos, como os de Scalcon (2008), Neves (2013), Shiroma e Evangelista (2014), Evangelista e Triches (2012), Souza e Magalhães, (2014), Brzezinsk (2008). No conjunto, as propostas dos autores delineiam opções epistemológicas vinculadas à concepção da relação teoria-prática como práxis. Esses estudos refletem sobre como parte da produção acadêmica do conhecimento tem sustentado políticas de formação e de profissionalização de professores orientados pela lógica mercadológica.

Souza e Magalhães (2014), ao analisarem a produção acadêmica sobre professores, mostram que, para os trabalhos fundamentados na epistemologia da prática, a meta da formação é o chamado professor reflexivo, caracterizado por se limitar a pensar a própria prática; conceber o conhecimento apenas como resultante da 


\section{autêntica}

experiência no trabalho, privado de sistematização teórica. Nessa concepção de formação, há a secundarização de fundamentos teóricos, portanto de desvalorização da práxis, conforme já discutido.

Essas ideias são aprofundadas com as considerações de Evangelista e Triches (2012). Ambas afirmam que as diretivas elaboradas para os cursos de formação de professores, sobretudo após a década de 1990, caracterizam-se por apresentar uma política de formação para a "reconversão docente" e a produção do consentimento ativo, como estratégia neoliberal de manutenção do status quo. Para essas autoras, a reconversão profissional apoia-se no alargamento e na restrição do conceito de docência. Alargamento, pois converge à ideia de superprofessor; restrição, pois fecha-o para a dimensão política do trabalho docente, caracterizando o exercício da profissão como Pedagogia da Hegemonia (NEVES, 2013).

Teoricamente, a epistemologia da prática é apresentada por Tardif ${ }^{3}$ como marco essencial para a formação dos professores e para resolver problemas relativos à sua profissionalização e identidade. Para esse autor, essa epistemologia refere-se ao estudo do conjunto dos saberes utilizados pelos profissionais nas suas tarefas. Tardif e Schön ${ }^{4}$ propõem a epistemologia da prática com esse fim e, quando assim o fazem, põem em relevo a questão da reorganização das estruturas de poder na escola, passando a aprendizagem a ser concebida como capacidades de reprodução do conhecimento (RODRIGUES, 2005).

Em relação à qualidade educacional, a epistemologia da prática é legitimada pelas orientações de organismos multilaterais, como o Banco Mundial, que defendem o conceito de qualidade educativa neoliberal para a formação e a educação. Dessa maneira, subtrai da educação e da formação sua relevância social, limitando-as às atividades técnicas, desligadas das dimensões política, ética, estética e cultural.

No entendimento de Souza e Magalhães (2014), essa concepção de qualidade neoliberal reduz a premissa ontológica da educação e do trabalho como constituidoras do sujeito social. Para essas autoras, embora o capitalismo destaque o trabalho como pressuposto da existência humana, o que realmente gera é a alienação do homem em relação ao seu trabalho e ao trabalho de seu produtor, ferindo o princípio fundamental e ontológico do trabalho, que é a omnilateralidade e a transformação da realidade, conforme Marx (2006).

A assimilação, defesa e difusão dessa concepção são possíveis pela construção do consenso que visa dar legitimidade à ideologia neoliberal, movimento que se consolida na criação e na propagação de ideias que passam a ser aceitas pela sociedade, compreendidas e assumidas como indicadores da qualidade hegemônica da educação, implantados a partir da lógica regulatória.

Em contraposição, a Redecentro fundamenta-se na epistemologia da práxis para a construção de indicadores de qualidade social para a formação e a educação. A consolidação desses indicadores, no que se refere à formação, apoia-se nas análises desenvolvidas por Souza (2014), que recorreu à concepção de educação como Bildung, a partir de Hegel (1988). Para esse autor, a educação é entendida como processo integral de formação histórica; como caminho da consciência e do espírito para a liberdade. Segundo Souza (2014), a ideia de Bildung relaciona-se com o desenvolvimento interior do sujeito e de sua autonomia. Seu objetivo é realizar o pleno desenvolvimento do ser humano, como progresso pessoal e social e de autonomia do sujeito, o que implica resistência ao processo desumanizador e exige essencialmente postura ética e política.

3 Teórico relacionado à epistemologia da prática: TARDIF, Maurice. Saberes docentes e formação profissional. Petrópolis-RJ: Vozes, 2002.

4 Teórico relacionado à epistemologia da prática: SCHÖN, Donald A. Educando o profissional reflexivo: um novo design para o ensino e a aprendizagem. Trad. Roberto Cataldo Costa. Porto Alegre: Artes Médicas, 2002. 
Para os pesquisadores da Redecentro, essa perspectiva epistemológica, seu posicionamento ético-político e enfoque da pesquisa também permitem definir os indicadores de qualidade social do ideário pedagógico, que conceitua a educação como: "[...] processo humanizador de caráter técnico, político e social, que decorre de uma relação dialética entre a produção e a transmissão de conhecimentos, assumindo um potencial transformador da sociedade" (SOUZA; MAGALHÃES, 2014, p. 13).

Nessa mesma perspectiva epistemológica, sustentam-se indicadores de qualidade social da concepção de professor, assim definidos: sujeito historicamente situado, marcado pelas relações políticas, econômicas e culturais; produto e produtor da realidade social, cujo trabalho oportuniza construções diversas, de maneira crítica, aberta e autônoma, o que demanda a elaboração de conhecimentos emancipatórios. Os indicadores de qualidade social do processo ensino-aprendizagem o identificam como práxis. Quanto à escola, esta é parte inseparável da totalidade social e representa uma possibilidade de ruptura e de transformação da sociedade, ao proporcionar a construção do conhecimento emancipador (SOUZA; MAGALHÃES, 2014).

Em termos contra-hegemônicos, a Rede construiu os indicadores de qualidade social, conforme exemplificados, entendendo que a concepção de qualidade credita posições políticas, ideológicas e epistemológicas, que sustentam finalidades à produção do conhecimento, à formação e à educação. Nesse sentido, os indicadores de qualidade social expostos são agora considerados na análise do PNE 2014-2024.

\section{O PNE: SUA EPISTEMOLOGIA E QUALIDADE DEMANDADA À FORMAÇÃO E À EDUCAÇÃO}

Nesta seção, seguem-se os caminhos semelhantes ao que foi exposto até o momento: aborda-se o PNE a partir de alguns dos indicadores de qualidade social construídos pela Rede. Destacam-se as bases epistemológicas, as posições políticas e ideológicas assumidas, com foco na qualidade atribuída à formação e à educação.

Em entrevista concedida ao portal Anped, Saviani (2014) contextualiza o histórico de lutas que perpassa o PNE. Afirma que convivemos com a força do privado, concretizada no destaque dado aos interesses mercadológicos que contaminam a esfera pública e dificultam as ações dos que defendem educação pública de qualidade a toda população brasileira. Exemplifica essa ideia, analisando a influência, na rede pública, do movimento "Todos pela Educação (TPE)", dos sistemas "COC", "Objetivo", "Positivo", "Uno", "Anglo" etc., que prometem aumentar pontos na avaliação do IDEB, induzindo a adoção de seu material didático pelas Secretarias de Educação, em substituição aos livros didáticos distribuídos pelo MEC.

Da mesma maneira, o Coletivo de Estudos em Marxismo e Educação (COLEMARX, 2014) reflete que a organização criada pelo grupo de empresários "Todos pela educação (TPE)", conforme já fora denunciado por Saviani (2014), tornou-se parceira preferencial do governo e um dos principais agentes políticos da elaboração do PNE, em defesa dos interesses do capital. Essa organização advoga que a missão da educação é, em nome de sua qualidade e em conformidade com os ideais da epistemologia da prática, formar distintos recursos humanos e difundir competências úteis ao mercado. As orientações que dela emanam objetivam implementar meios de controle, a partir de sistemas padronizados de avaliação, e estabelecer novo "habitus" baseado nas ideias de meritocracia e de rankings para, de acordo com as pontuações alcançadas, manejar a prática de novas finalidades educativas a partir da distribuição de recursos financeiros. Diretivas como essas estimulam a competição entre escolas e professores como um valor a ser cultivado em todas as relações educativas, tanto as que ocorrem na escola como as que ocorrem fora dela. Autorizam-nos, assim, a questionar o conceito de qualidade empresarial da educação apresentado no PNE, focado em treinamento 


\section{autêntica}

de habilidades e competências, baseado na concepção dissociada de ensino e aprendizagem e na desvalorização da dimensão político-pedagógica do processo educativo.

Para os pesquisadores do COLEMARX (2014), desde quando a defesa dos $10 \%$ do PIB para a educação passou a ter visibilidade social, tanto o Governo Federal como os empresários do TPE passaram a fazer a defesa de sua aplicação, desde que não fosse exclusivo à educação pública. O COLEMARX (2014) ressalta que, nos termos do PNE, a formação docente constitui-se fonte de lucros para as grandes corporações, pois o Plano estimula que essa formação seja feita nas instituições privadas, com recursos do PROUNI e do FIES.

Por essa razão, Saviani (2014) afirma que o substitutivo ao projeto do PNE, que acabou sendo aprovado, significou um retrocesso, já que a partir daí os recursos públicos passaram a sustentar o ensino privado, debilitando a luta em defesa da ampliação da educação pública de qualidade social. O autor recorre à análise histórica para afirmar que o PNE anterior não passou de uma carta de intenções, tendo sido ignorado tanto pela política educacional como pelas instituições, e que o PNE em vigência corre o mesmo risco. Para que o Plano seja viável é imprescindível a aplicação dos recursos financeiros à educação pública, sem os quais as metas não serão atingidas. A luta em defesa dos recursos para a educação pública enfrenta interesses antagônicos do empresariado neoliberal, aspecto muito discutido por Brzezinski (2012) e Saviani (2014).

Para a compreensão epistemológica do PNE, é importante analisar a concepção de qualidade da educação defendida por ele. Associada a essa concepção está a concepção de qualidade da formação, que é coligada à da profissionalização e à do trabalho docente, o que inclui as condições salariais e de carreira que se ligam à valorização social da profissão.

Há dois aspectos asfixiantes inerentes à articulação dessa temática pontuados por Saviani (2014). Um deles diz respeito à questão da carreira, do piso salarial, da jornada de trabalho. Com relação a essa última, Saviani defende que a jornada docente seja exercida em uma única escola, com até $50 \%$ do tempo destinado à sala de aula e o restante às outras atividades do trabalho pedagógico. O outro aspecto diz respeito ao lócus da formação docente. O autor adverte sobre a necessidade de se criarem condições de formação docente nas universidades públicas, já que, no atual contexto de políticas educativas neoliberais, a maioria dos professores que atua nas escolas públicas é formada em instituições particulares de ensino de precária qualidade. A ideologia do ensino privado, de caráter mercantil, dominante na formação desses professores, aliena e inviabiliza que se trabalhe em prol da qualidade social da educação.

É importante ressaltar que o discurso do PNE abriga interesses hegemônicos que consideram a educação como mercancia, cujo fim é formar e difundir o consenso ativo ${ }^{5}$ entre educadores, pais, alunos, comunidade (SOUZA; MAGALHÃES, 2014). Não se pode deixar de considerar, portanto, que o documento, como projeto político-institucional, reflete interesses econômicos, sociais e culturais contraditórios àqueles defendidos pelas associações, movimentos sociais, entidades científicas em prol de uma educação pública de qualidade socialmente referendada.

\footnotetext{
5 Conforme Souza e Magalhães (2015, p. 03): O consenso ativo é uma das estratégias da classe dominante para se tornar também classe dirigente, seja como coerção, ou como consenso, quer dizer, assumindo a direção intelectual e moral do processo social. Sua produção tem o objetivo de consolidar a acreditação e aprovação das políticas educacionais. O consenso é fundamental para a constituição da hegemonia, promove a regulação que é essencial para a introdução de uma nova sociabilidade na educação, capaz de envolver professores, alunos, dirigentes educacionais, pais, comunidade, em um mesmo projeto.
} 
Merece registro o que a análise aponta: as metas 15, 16, 17 e 18 do PNE, referentes à formação (15 e 16) e às condições de exercício docente (17 e 18), não apresentam soluções às questões até aqui colocadas, pois não asseguram a formação ancorada nas instituições públicas e não garantem o correto desenvolvimento da profissionalização docente. Mais uma vez concorda-se com o argumento de que, sem que haja metas claras e condições para resolver as questões da formação e do trabalho docente, não há como se falar da melhoria da qualidade social da educação pública. Brzezinski (2012) alerta sobre a importância de deixar claro que a luta é pela qualidade social, pela qual a educação é entendida como conhecimento, em contraposição aos pressupostos neoliberais que defendem a qualidade total, pela qual a educação torna-se mercadoria.

No contexto do projeto do PNE, com visíveis vínculos à epistemologia da prática, o trabalho dos professores parece ter que se restringir ao treinamento, comprometendo, assim, a identidade docente como intelectual transformador, crítico, contra-hegemônico. O Plano institui o critério meritocrático para a definição dos salários dos professores, tergiversa a reivindicação histórica do piso salarial, compromete sua valorização e carreira.

As propostas do PNE estão afastadas das propostas de Brzezinski (2012, p 14), que faz a defesa de uma formação de caráter omnilateral e da universidade pública como lócus dessa formação, pois nela o trabalho docente e a pesquisa têm mais possibilidades de se concretizarem como princípios formativos, articulados socialmente. Quanto à formação ainda, a autora defende que o Plano reflita a concepção de formação que se funda no pensamento crítico, na relação dialética entre teoria e prática, no trabalho coletivo e interdisciplinar, no compromisso social articulado aos movimentos sociais e sindicais, na gestão democrática, como expressão do significado social das relações de poder na escola. Quanto à profissionalização dos professores, Brzezinski propõe que essa esteja referendada na qualidade social, com a garantia de condições de trabalho e salariais ao longo da carreira docente.

A partir desse estudo do PNE, podemos, num esforço de síntese, sustentar que a sua perspectiva epistemológica, a teoria geral que o fundamenta é o positivismo. Seu posicionamento político ideológico é neoliberal, o que mostra que o documento traduz uma concepção de qualidade hegemônica, conceitos e concepções fundadas na epistemologia da prática, conforme já exposto. Evidencia-se que nele a formação distancia-se da Bildung (SOUZA, 2014) e que seu enfoque metodológico reflete uma concepção que dissocia a relação teoria e prática; a educação torna-se mercadológica, pois ignora-se o caráter histórico das relações sociais, silenciando-se a perspectiva de transformação social.

\section{A PESQUISA ACADÊMICA SOBRE PROFESSORES, SEU CAMPO EPISTEMOLÓGICO E O PNE 2014-2024}

Para refletir sobre o PNE 2014-2024, colocando-o em relação à qualidade educacional, à formação e à educação, recorre-se à análise da produção acadêmica sobre professores. Isso por considerá-la, de um lado, formadora, divulgadora e mantenedora de racionalidades que sustentam, epistemologicamente, políticas educacionais, como o referido documento, contribuindo para inviabilizar a qualidade social da educação; e de outro, contestadora da hegemonia e formadora de um pensamento crítico que pode, inclusive, inspirar políticas educacionais de caráter emancipador.

Para expressar essa articulação, a partir da produção acadêmica, optou-se por um recorte das pesquisas desenvolvidas na perspectiva dialética, do Programa de Pós-Graduação em Educação, da Faculdade de Educação, Universidade Federal de Goiás, no período de 1999-2009, em que foram defendidos 317 trabaIhos, dos quais 277 dissertações e 40 teses. Desse conjunto, 109 trabalhos versaram sobre professores. O foco da análise serão os indicadores de qualidade social para método, ideário pedagógico (educação, 


\section{autêntica}

escola, professor, e processo ensino-aprendizagem) e formação, conforme posicionamento epistemológico, princípios e concepções da dialética, já discutidos.

Os indicadores de qualidade social referentes ao método materialista histórico- dialético foram construídos a partir de oito critérios: 1) abordar o objeto na perspectiva histórica, a partir de suas origens; 2) buscar na história as origens do problema, do todo e não de tudo; 3) trabalhar com os sujeitos típicos a serem pesquisados; 4) apresentar o concreto pensado, evidenciando o objeto que estava oculto, o movimento dialético; 5) utilizar categorias marxistas para análise - trabalho, alienação, ideologia, classe social, contradição, negação, totalidade, universalidade; 6) articular teoria e prática e denominá-la práxis; 7) apresentar os dados, evidenciando seus nexos internos e contraditórios com a totalidade; 8) referencial teórico utilizado. Em relação a essa última categoria, observa-se, na produção analisada pela Rede, uma mudança gradual de posicionamento dos pesquisadores, que vão atribuindo ao método a importância devida na construção da pesquisa. Isso se deve, em parte, ao trabalho que a Rede vem desenvolvendo em seus programas.

No período 1999-2005, foram defendidas 179 trabalhos, sendo 177 dissertações e duas teses. Desse total, 72 versaram sobre a temática professores. Constatou-se, a partir das análises, que, em $24 \%$ dos trabalhos, o método estava claramente explicitado - não estava em $62 \%$, mas poderia ser identificado. Em $14 \%$ dos trabalhos não foi possível identificar o método. É representativo o fato de $62 \%$ dos trabalhos não especificarem o método utilizado, o que pode ser compreendido pelo fato de que a especificação ou a declaração do método adotado, por parte dos autores, não era, no período estudado, uma prática assumida pelos pesquisadores nos programas de pós-graduação.

No que se refere aos indicadores de qualidade social, pode-se observar que, durante o período de 19992005, as pesquisas trabalharam adequadamente os indicadores 1 a 4, que representam a construção da historicidade do objeto de estudo. Os pontos nevrálgicos na construção foram os indicadores 5 a 8, ou seja, o concreto pensado, a construção de categorias marxistas, a articulação entre teoria e prática denominando-a práxis, o que indica inconsistência epistemológica. No mesmo recorte, há ausência de referencial teórico clássico e teórico-metodológico (SOUZA; MAGALHÃES, 2011; 2014).

No período 2006-2007, foram defendidos 64 trabalhos, sendo 46 dissertações e 18 teses. Do total de 64 trabalhos produzidos, 17 versaram sobre a temática professores. Desses, 40\% explicitaram o método; 40\% não o explicitaram, mas pode ser identificado; em 10\% identificou-se indistinção entre método e metodologia; e em 10\% não houve a explicitação nem foi possível a identificação do método. Embora tenha sido constatado o aumento de trabalhos que explicitaram o método, no entendimento da Rede, ainda houve mais de $50 \%$ de trabalhos com incoerência epistemológica.

Quanto aos indicadores de qualidade, pode-se observar que, durante o período de 2006-2007, as pesquisas apresentaram os mesmos problemas na construção dos indicadores 3, 5 a 8, ou seja, trabalhar com os sujeitos típicos; construir o concreto pensado, utilizar categorias marxistas; articular teoria e prática e denominá-la práxis; apresentação dos dados, evidenciando seus nexos internos e contraditórios com a totalidade. No entanto, ressalta-se uma mudança qualitativa no mesmo período no que se refere à presença de referencial teórico clássico e teórico-metodológico em $60 \%$ dos trabalhos.

No intervalo 2008-2009, foram defendidas 74 trabalhos, sendo 54 dissertações e 20 teses. Do total de 74 trabalhos produzidos, 17 versaram sobre a temática professores. Observou-se significativa elevação da 


\section{autêntica}

qualidade das pesquisas, atribuída à construção adequada de indicadores de qualidade social e de referencial teórico clássico e teórico-metodológico. A Rede interpreta que houve adequação epistemológica. Durante o mesmo período, os programas de pós-graduação mostraram-se motivados para promover seminários que abordaram as questões relacionadas à pesquisa da Rede. Outra repercussão importante foi o fato de a pesquisa ter sido tema de estudo em disciplinas de programas de pós-graduação, como, por exemplo, na UFG, em "Formação de professores: pesquisas e perspectivas críticas", e na UNIUBE, em "Pesquisa em educação: a produção científica sobre o professor na Região Centro-Oeste". Isso permite interpretar que, de certa maneira, o movimento da Redecentro tem contribuído com a formação dos pesquisadores.

Quanto ao ideário pedagógico estabeleceram-se quatro indicadores de qualidade social: 1) conceituação; 2) explicitação de intencionalidade; 3) posicionamento político; 4) referencial teórico-metodológico. Na pesquisa da Rede, observou-se, no período de 1999-2009, elevado índice de trabalhos,95\%, que se autodenominaram críticos. Na análise do referencial teórico, observou-se que, no período de 1999-2007, houve explícita contradição no conjunto dos trabalhos: alguns não fazem distinção entre proposições referendadas numa epistemologia crítica e numa epistemologia da prática. Isso se caracteriza como um equívoco epistemológico, uma vez que os trabalhos não diferenciam autores que se filiam declaradamente à perspectiva hegemônica daqueles que se filiam à linha crítica dialética. Na análise do ideário pedagógico, observou-se a citação de autores clássicos da linha crítica, mas apenas como simples ilustração, pois não são utilizados na construção de conceitos centrais.

Alguns pesquisadores se autodenominam críticos, mas constroem conceitos contraditórios, que sustentam explicitamente uma epistemologia da prática e a lógica neoliberal. Dão ênfase, por exemplo, à responsabilização do professor por toda mudança educacional e social e por seu êxito:

[...] no trabalho realizado pelo professor, caberá a ele incorporar as mudanças em todo o processo educacional e na sua atuação em sala de aula. Nos ciclos, o trabalho docente é realizado pelo coletivo de professores, que se torna responsável não só pelas mudanças necessárias, inclusive as curriculares, como também pela própria continuidade da proposta (REDECENTRO - Trabalho 119, p. 111. Ano 2009). [Grifos nossos].

Na citação acima se observa que o autor atribui aos professores poderes desproporcionais, conforme discutido com Triches e Evangelista (2014, p.67), o que favorece a reconversão do "ser professor", influindo diretamente na desconstrução da sua identidade porque o desqualifica pelo processo de formação. Os professores, ao se sentirem incapazes de responder a tantas responsabilizações, questionam a qualidade de sua formação e a sua função social.

A fragilidade epistemológica observada nos trabalhos do período de 1999-2007 é superada na produção do período de 2008-2009. Identificaram-se trabalhos que contradizem a lógica neoliberal, sustentam a perspectiva crítica contra-hegemônica, particularmente crescente no movimento da produção. Vejamos alguns exemplos do ideário pedagógico:

[...] A educação pública, um direito social essencial à classe trabalhadora (REDECENTRO - Trabalho 123, Ano 2009, p. 163). [Grifo nosso].

[...] Mais do que se comprometer com a eliminação do fracasso escolar, reduzindo os índices de evasão e repetência, caberá à escola e ao professor comprometer-se com o conhecimento produzido 


\section{autêntica}

pela humanidade e com uma escola pública unitária, de qualidade, que busque no conjunto das relações sociais uma formação humana sólida, crítica e transformadora (REDECENTRO - Trabalho 119, Ano 2009, p. 110). [Grifo nosso].

[...] A escola não é encarada como mera reprodutora do sistema, podendo desenvolver em seu interior e à revelia dos determinismos do capitalismo, uma contra-educação (REDECENTRO Trabalho 126, Ano 2009, p. 239). [Grifo nosso].

[...] os professores devem ser (...) sujeitos mais autônomos, conscientes de seus direitos e deveres como profissional e cidadão (REDECENTRO - Trabalho 113, Ano 2008, p.77). [Grifo nosso].

[...] ensino aprendizagem é histórico, cultural e social (...) é processo de humanização (...) possibilita um olhar crítico e uma leitura reflexiva sobre as questões que envolvem todo o processo educacional e, consequentemente, possibilitam articular a teoria e a prática de forma contextualizada, significativa para o educando, visando a uma práxis transformadora e inovadora (REDECENTRO - Trabalho 113, Ano 2008, p. 48). [Grifo nosso].

Quanto à concepção de formação, nos trabalhos do período de 2008-2009, observou-se a apropriação da base teórica da dialética e a conceituação de formação como práxis em articulação com a relevância social do professor, com seu compromisso político e ético frente à educação.

[...] A formação deve [...] propiciar melhores condições para o exercício profissional (...) contribuindo para a transformação nos campos social, econômico, cultural e humano do cidadão no Estado de Goiás (REDECENTRO - Trabalho 6, Ano 2007, p. 81). [Grifo nosso].

[...] a formação (...) processo como um compromisso político e ético que lhes permita compreender a profissão de tal maneira que os faça aderir e se identificar como os compromissos próprios da tarefa docente (REDECENTRO - Trabalho 127, Ano 2009, p. 54). [Grifo nosso].

[...] a formação ajuda constituir (...) identidade política que é percebida como o processo de configuração de autoconsciência de um grupo, em que ele elabora sua posição e ação diante dos conflitos sociais e relações de poder (...) (REDECENTRO - Trabalho 123, Ano 2009, p. 15). [Grifo nosso].

Os indicadores de qualidade sinalizam que, no que se refere à formação docente, os trabalhos do período de 2008-2009 são propositivos; assumem a prática pedagógica e a pesquisa acadêmica como práxis; situam-se contra a reprodução da hegemonia. Nesse sentido, respondem aos requisitos de qualidade social que perseguimos.

Ao adotar a epistemologia como ponto de partida para a análise do PNE, colocando-a em relação à produção acadêmica com foco na formação e na educação, identificou-se que, no caso da produção acadêmica do período de 1999-2007, há a presença da racionalidade da epistemologia da prática, o que favorece a construção de conceitos que atendem às demandas neoliberais. No caso da produção do período seguinte, 2008-2009, há a presença marcante da epistemologia da práxis, cuja racionalidade respeita as mediações de caráter histórico, cultural e social, como processo fundante de desenvolvimento do ser social, de humanização do homem, o que leva a caracterizar essa produção como contra-hegemônica. Tanto no campo da produção do conhecimento como no caso do PNE, expressam-se forças antagônicas. Em relação à política expressa no PNE, a epistemologia da prática mostra-se predominante na produção das racionalidades, fortalecendo 
a hegemonia. Conclui-se, advertindo para a necessidade da cautela epistemológica e alertando para a concepção de qualidade proposta à formação e à educação no documento. Isso significa que os pesquisadores precisam mantem vigilância epistemológica, para que seus estudos e publicações possam ser conduzidos por meio da epistemologia da práxis, a qual, no nosso entendimento, favorece o posicionamento político contra hegemônico e, consequentemente, a defesa de uma educação pública de qualidade socialmente referendada.

\section{ALGUMAS CONSIDERAÇÕES}

O campo da pós-graduação tem alicerçado o movimento de construção da "Nova Pedagogia da Hegemonia", por duas vias: primeira, porque pode sustentar conceitos, ensinar, divulgar, consolidar práticas que correspondem aos princípios da hegemonia; segunda, porque o mesmo movimento de produção pode promover um discurso de aparência crítica, mas cujas bases teóricas, contraditoriamente, fundam-se nos mesmos princípios ideológicos que representam a "Terceira Via" (NEVES, 2013).

No recorte analisado, alguns trabalhos, mesmo seus autores se autodefinindo como críticos, ainda trilham o caminho da epistemologia da prática e não dão sustentação à concepção de qualidade social da educação. Pelo contrário, reforçam aspectos políticos e ideológicos neoliberais, cuja racionalidade se mostra presente na estrutura do PNE.

Pretendeu-se discutir a importância da compreensão epistemológica da produção acadêmica e do PNE para evidenciar seus pressupostos e fundamentos e, assim, esclarecer a que objetivos político-ideológicos se vinculam e as possíveis repercussões dessa vinculação. A análise epistemológica aqui empreendida mostra que, no caso da produção acadêmica, identifica-se o confronto entre as finalidades dos trabalhos e sua construção epistemológica. A contradição está posta. Alguns se filiam à epistemologia da prática e ajudam na manutenção dos interesses empresariais, outros à epistemologia da práxis e podem contribuir com o movimento de emancipação. Já no caso do PNE, identifica-se filiação à manutenção dos interesses mercadológicos, sem nenhuma contradição.

Essas posições epistemológicas, políticas e ideológicas creditam e sustentam as finalidades da educação, da formação docente, deliberando sua qualidade, além de sustentar a racionalidade que alicerça as políticas educacionais. Nesse sentido, defende-se que o campo precisa manter o rigor epistemológico crítico contra-hegemônico para contribuir com a discussão, com vistas à transformação das políticas públicas, conferindo-lhes significados sociais, éticos e políticos emancipadores. A Rede entende que a vigilância epistemológica pode mediar a constituição de pensamento que objetive a práxis e nela influir, fazendo com que, assim, a produção da pós-graduação, no que se refere à racionalidade propagada, deixe de engrossar a fileira de autores ligados à epistemologia da prática, os quais contribuem para a definição da qualidade da educação como slogans neoliberais, conforme Shiroma e Santos (apud EVANGELISTA, 2014) apontam, prontos para serem usados e divulgados em qualquer perspectiva de trabalhos educacionais, como nas proposições do PNE.

Conclui-se, em consonância com os trabalhos de fundamentação teórico-crítica a que se recorreu, que se faz necessário superar a reprodução de discursos alienantes no campo da pesquisa acadêmica, para que não sustentem a lógica neoliberal na produção e na validação de políticas educacionais, como é o caso do PNE. A pesquisa acadêmica deve, pois, responsabilizar-se por formar professores pesquisadores envolvidos com a lógica emancipadora, que legitima e referenda a qualidade social para a formação docente e a educação. 


\section{autêntica}

\section{REFERÊNCIAS}

BRZEZINSKI, Iria. Políticas contemporâneas de formação de professores para os anos iniciais do ensino fundamental. Revista Educ. Soc., Campinas, vol. 29, n. 105, p. 1139-1166, set./dez., 2008.

BRZEZINSKI, Iria. Entrevista professora Dra. Edite Maria Sudbrack, Coordenadora do Mestrado em Educação da URI/FW, em Goiânia, 5 de julho de 2012. Revistas de Ciências Humanas, Goiânia, vol.13, n.20, p.11-27 2012.

COLEMARX. Coletivo de Estudos em Marxismo e Educação. ADUFRJ. Plano Nacional de Educação, 20112020. Notas Críticas, 2014

DUARTE, Newton. Vigotski e o Aprender a Aprender: crítica às apropriações Neoliberais e Pós-Modernas da Teoria Vigotskiana. Campinas: Autores Associados, 2000.

EVANGELISTA, Olinda; TRICHES, Joseleia. Professor: a profissão que pode mudar um país? In: EVANGELISTA, Olinda (Org.). O que revelam os slogans da política educacional. Araraquara. São Paulo: Junqueira-Marin, 2014.

FREIRE, Paulo. Pedagogia da Autonomia. São Paulo: Paz e Terra, 1997.

EVANGELISTA, Olinda; TRICHES, Joseleia. Curso de Pedagogia, organizações multilaterais e o superprofessor. Educar em Revista. Curitiba: Editora UFPR, n. 45, p. 185-198, jul./set. 2012.

GRAMSCI, Antônio. Concepção dialética da história. 8. ed. Rio de Janeiro: Civilização Brasileira, 1989.

HEGEL, Georg W. Friedrich. Principios de la Filosofía del Derecho. Trad. Juan L. Vermal. Barcelona: EDHASA, 1988.

KUENZER, Acácia Z.; RODRIGUES, Marli F. As diretrizes curriculares para o curso de Pedagogia: uma expressão da epistemologia da prática. Olhar de Professor, Ponta Grossa, Paraná, v. 1, p.35-62. 2007.

MARX, Karl. O Capital: crítica da economia política. Livro I, Vol. I. 24ª ed. Trad. Reginaldo Sant'Anna. Rio de Janeiro: Civilização Brasileira, 2006.

MORAES. M. C. M. Recuo da teoria. In: MORAES, M. C. M. et al. Iluminismo às avessas: produção de conhecimento e políticas de formação docente. Rio de Janeiro: DP\&A, 2004.

NEVES, Lúcia Maria Wanderley. O professor como intelectual estratégico na disseminação da nova pedagogia da hegemonia. Anais da 36ª Reunião Nacional da ANPEd. Goiânia, 2013.

RODRIGUES, Marcio de F. Da Racionalidade Técnica à "Nova" Epistemologia da Prática: a proposta de formação de professores e pedagogos nas Políticas Oficiais Atuais. Tese de Doutorado. Programa de PósGraduação em Educação, Doutorado em Educação, Universidade Federal do Paraná, 2005.

SANTOS, Boaventura de Souza. A Crítica da Razão Indolente: contra o desperdício da experiência. Porto: Afrontamento, 2000. 


\section{autêntica}

SAVIANI, Dermeval. Epistemologia de las politicas educativas: algumas precisiones conceptuales. In: TELLO, Cesar. Epistemologia de la pólitica educativa. Campinas, São Paulo: Mercado de letras, 2013.

SAVIANI, Dermeval. Entrevista no Portal Anped. Plano Nacional de Educação (PNE) 2014. Disponível em http://www.anped.org.br/news/entrevista-com-dermeval-saviani-pne. Acesso em 26/10/2016

SAVIANI, Dermeval. A Pedagogia Histórico-crítica: Primeiras aproximações. São Paulo. Cortez: Autores Associados, 1991

SCALCON, Suze. O pragmatismo epistemológico e a formação do professor. Revista Percursos, Florianópolis: UDESC, v. 09, n. 02, 2008.

SEVERINO, Antônio J. Preparação técnica e formação ético-política dos professores. In: LAZZARI Raquel (Org.) Formação de educadores: desafios e perspectivas. Organizadora Raquel Lazzari Leite Barbosa. São Paulo: Editora UNESP, 2003.

SHIROMA, Evangelista; EVANGELISTA, Olinda. Luzes que deslumbram: uma análise dos slogans na política educacional. In: EVANGELISTA, O. (Org.). O que revelam os slogans da política educacional. Araraquara. São Paulo: Junqueira-Marin, 2014.

SOUZA, Ruth Catarina C. R. de; MAGALHÃES, Solange M. O. Pesquisa educacional: uma análise epistemológica da produção acadêmica sobre professores. Anais do XII Encontro de Pesquisa em Educação da Região Centro-Oeste. Programa de Pós-Graduação em Educação e da Pontifícia Universidade Católica de Goiás-PUC Goiás, 2014. Prelo.

SOUZA, Ruth Catarina C. R. de; MAGALHÃES, Solange M. O. Qualidades Epistemológicas e Sociais na Formação, Profissionalização e Prática dos Professores. In: SOUZA, R. C. C. R. de; MAGALHÃES, S. M. O. Poiésis e Práxis II - Formação, profissionalização, práticas pedagógicas. Goiânia: Kelps, 2014.

TELLO, Cesar. Epistemologia de la pólitica educativa. Campinas, São Paulo: Mercado de Letras, 2013.

VYGOTSKI, Lev S. Obras Escogidas, Vol. III. Madrid: Visor, 1995.

VAZQUEZ, Adolfo Sanchez. Filosofia da práxis. 4. ed. Rio de Janeiro: Paz e Terra, 1986. 